Supporting Information

\title{
Nanodiamond Solid Phase Extraction and Triton X-114 Cloud Point Separation for Robust Fractionation and Shotgun Proteomics Analysis of Human Serum Proteome
}

Hai Lam Khuong1, Chein-Hung Chen ${ }^{2}$, Jung-Lee Lin ${ }^{2}$, Trong-Nghia Le ${ }^{3}$, Thi Hue Pham ${ }^{1}$, Thi Bich Thao Le ${ }^{1}$, Xuan Canh Nguyen ${ }^{4}$, Van Chi Phan ${ }^{1}$, Hoang Ha Chu ${ }^{1}$, Wesley Wei-Wen Hsiao $^{3 *}$, Thi Minh Phuong Nguyen ${ }^{1 *}$, Dinh Minh Pham ${ }^{1 *}$

${ }^{1}$ Institute of Biotechnology, Vietnam Academy of Science and Technology, 18 Hoang Quoc Viet, Cau Giay, Hanoi, 100000, Vietnam.

${ }^{2}$ Genomic Research Center, Academia Sinica, Nankang, Taipei, 115, Taiwan.

${ }^{3}$ Department of Chemical Engineering, National Taiwan University of Science and Technology, Taipei, 106335, Taiwan.

${ }^{4}$ Faculty of Biotechnology, Vietnam National University of Agriculture, Gia Lam, Hanoi, 100000, Vietnam.

Figure S1. The SDS-PAGE comparison between supernatant and the
pellets....................2

Figure S2. GRAVY point distribution. The results were calculated on all 663 proteins identified.

Figure S3. Low-abundance proteins overlapping sections between three fractions of the same

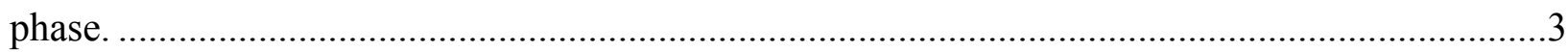

Table S4. Statistically summary of the six fractions, assessing the GRAVY point and

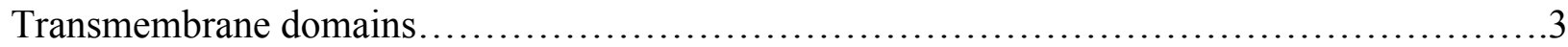

\section{Contents of supporting information xlsx file}

Table S1. List of 663 proteins identified in this work.

Table S2. Low abundance proteins.

Table S3. FDA-approved biomarkers. 


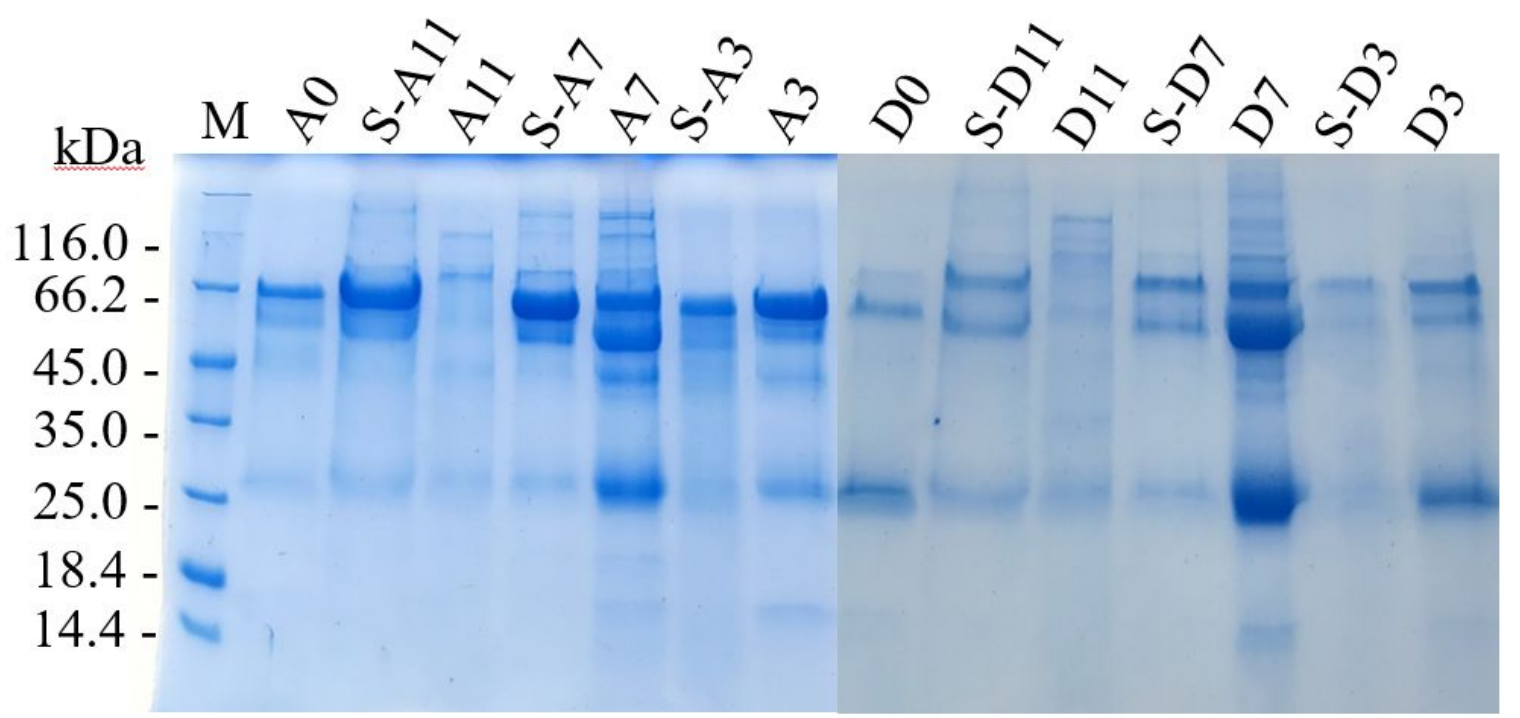

Figure S1. The SDS-PAGE comparison between supernatant and the pellets. S is for supernatant (the supernatant of each respective pellet). A0, D0 were obtained by capturing the A-phase and D-phase solution (before consecutive fractionation) with $50 \mu \mathrm{L} \mathrm{ND}(10 \mu \mathrm{g} / \mu \mathrm{L}$, excessive amount).

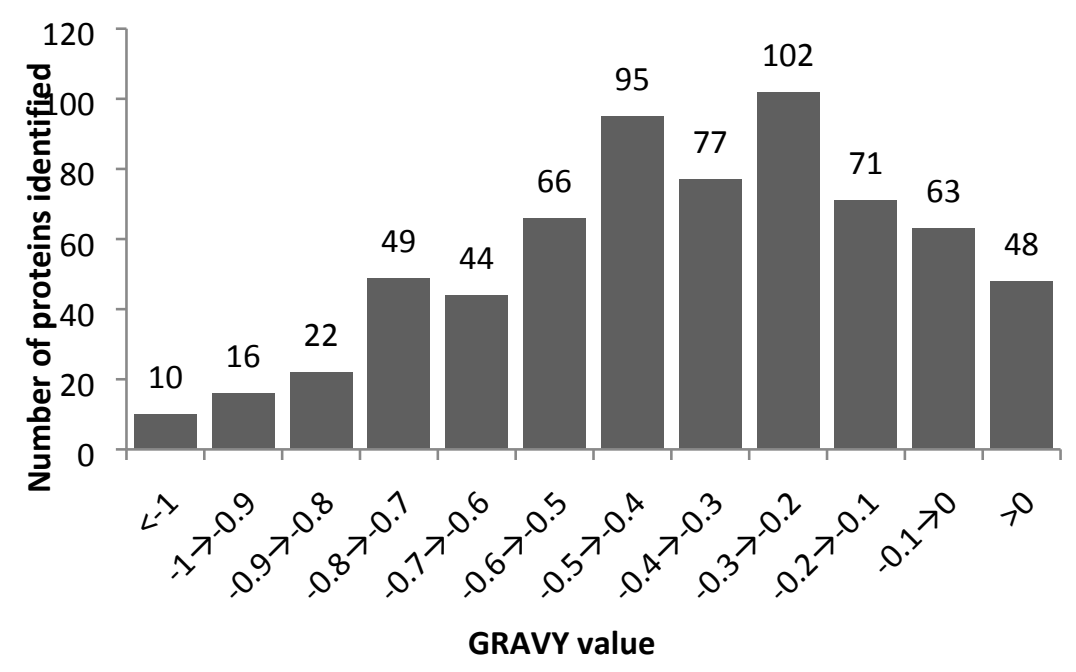

Figure S2. GRAVY point distribution. The results were calculated on all 663 proteins identified. 
(a)

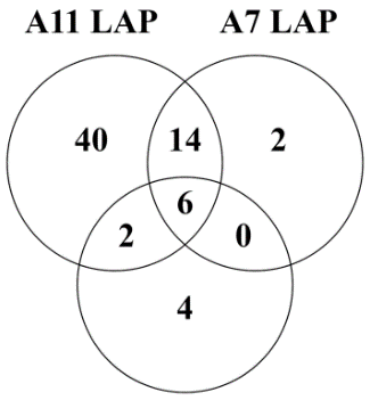

A3 LAP (b) D11 LAP D7 LAP

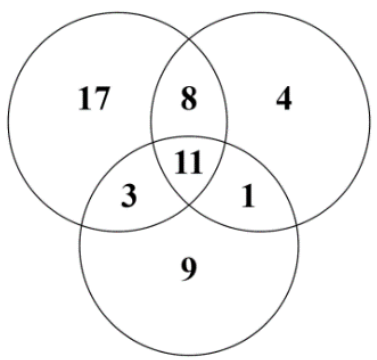

D3 LAP

Figure S3. Low-abundance proteins overlapping sections between three fractions in AP (a) and DP (b).

Table S4. Statistically summary of the six fractions, assessing the GRAVY point and Transmembrane domains

\begin{tabular}{|c|c|c|c|c|c|c|c|}
\hline Phase & Fraction & $\begin{array}{c}\text { Number of } \\
\text { protein }\end{array}$ & $\begin{array}{c}\text { Membrane } \\
\text { protein }\end{array}$ & GRAVY $>0$ & $\mathbf{T M}=\mathbf{0}$ & $\mathbf{T M}=1$ & $\mathrm{TM} \geq 2$ \\
\hline \multirow{3}{*}{$\begin{array}{c}\text { Aqueous } \\
\text { phase }\end{array}$} & pH11 & 363 & $\begin{array}{c}176 \\
(48.48 \%)\end{array}$ & $\begin{array}{c}19 \\
(5.23 \%)\end{array}$ & $\begin{array}{c}334 \\
(92.01 \%)\end{array}$ & $\begin{array}{c}\mathbf{2 5} \\
(6.89 \%)\end{array}$ & $\begin{array}{c}\mathbf{4} \\
(1.1 \%)\end{array}$ \\
\hline & pH7 & 272 & $\begin{array}{c}136 \\
(50 \%)\end{array}$ & $\begin{array}{c}21 \\
(7.72 \%)\end{array}$ & $\begin{array}{c}\mathbf{2 5 3} \\
(93.01 \%)\end{array}$ & $\begin{array}{c}16 \\
(5.88 \%)\end{array}$ & $\begin{array}{c}\mathbf{3} \\
(1.11 \%)\end{array}$ \\
\hline & pH3 & 225 & $\begin{array}{c}118 \\
(52.44 \%)\end{array}$ & $\begin{array}{c}23 \\
(10.22 \%)\end{array}$ & $\begin{array}{c}211 \\
(93.78 \%)\end{array}$ & $\begin{array}{c}\mathbf{8} \\
(3.55 \%)\end{array}$ & $\begin{array}{c}\mathbf{6} \\
(2.67 \%)\end{array}$ \\
\hline \multirow{3}{*}{$\begin{array}{c}\text { Deterge } \\
\text { nt-rich } \\
\text { phase }\end{array}$} & pH11 & 297 & $\begin{array}{c}143 \\
(48.15 \%)\end{array}$ & $\begin{array}{c}15 \\
(5.05 \%)\end{array}$ & $\begin{array}{c}\mathbf{2 7 2} \\
(91.58 \%)\end{array}$ & $\begin{array}{c}19 \\
(6.4 \%)\end{array}$ & $\begin{array}{c}\mathbf{6} \\
(2.02 \%)\end{array}$ \\
\hline & pH7 & 312 & $\begin{array}{c}169 \\
(54.17 \%)\end{array}$ & $\begin{array}{c}33 \\
(10.58 \%)\end{array}$ & $\begin{array}{c}281 \\
(90.06 \%)\end{array}$ & $\begin{array}{c}19 \\
(6.09 \%)\end{array}$ & $\begin{array}{c}12 \\
(3.85 \%)\end{array}$ \\
\hline & pH3 & 272 & $\begin{array}{c}145 \\
(53.31 \%)\end{array}$ & $\begin{array}{c}24 \\
(8.82 \%)\end{array}$ & $\begin{array}{c}\mathbf{2 5 6} \\
(94.11 \%)\end{array}$ & $\begin{array}{c}12 \\
(4.41 \%)\end{array}$ & $\begin{array}{c}4 \\
(1.47 \%)\end{array}$ \\
\hline
\end{tabular}

